\title{
Environmental consultants, knowledge brokering and policy-making: a case study
}

Ana Margarida Sardo ${ }^{1,+}$ and Emma Weitkamp ${ }^{1}$

Science Communication Unit, University of the West of England, Bristol, UK

${ }^{+}$Corresponding author:
A. Margarida Sardo
Faculty of Environment and Technology
University of the West of England
Frenchay Campus, Coldharbour Lane
Bristol BS16 1QY
UK
Email: margarida.sardo@uwe.ac.uk

\section{Biographical notes}

Ana Margarida Sardo is a Research Fellow and Associate Lecturer in Science Communication and a trained scientist with extensive experience in evaluating and delivering science communication projects. Her research interests include informal learning, generic venues in science communication, science contributions to environmental policy-making and evaluation methodologies.

Emma Weitkamp is an Associate Professor in Science Communication at the University of the West of England, Bristol where she teaches on an MSc in Science Communication and provides training in science communication for practitioners and Ph.D. students. Her research interests explore the ways that information moves from academia into the pubic sphere. 


\begin{abstract}
This small-scale exploratory study examined the role of environmental consultants in the policy-making process using one European country (Portugal) as a case study. The study focused particularly on the role of environmental consultants as knowledge brokers, providing scientific expertise to national and local government policy-makers. The research question and other topics were explored through in depth interviews and an online questionnaire. The data indicate that in Portugal environmental consultants act as knowledge brokers, providing policy-makers with access to scientific information and encouraging its use; this information feeds into the policy process at the formulation, implementation, assessment and review stages. They also play other roles such as acting as financial, legal and technical advisors.
\end{abstract}

Keywords: environmental consultants, policy-making, mediation, consultation, knowledge brokers.

\title{
1. Introduction
}

The demand for policies underpinned by scientific research comes from around the world, both from the public and scientists, as well as policy-makers. This positive interest has led to strong support for more prominent roles for scientists in the policy process (Sardo and Weitkamp, 2012; European Commission, 2008; Steel at al., 2004) and there is a view that scientists ought to be more involved in the policy process, as sources of objective information (Mazur, 1981). The importance placed on research in evidence- 
based policy-making comes from the recognition that, by increasing and clarifying the available alternatives, and by allowing decision-makers to achieve desired outcomes, "useful scientific information improves environmental decision-making" (McNie, 2007, p.17). A recent study suggests that in order to better account for the complexity of environmental decision-making, policy-makers should "further strengthen a culture of policy-relevant research and evidence-based policy on environment issues by fostering more decentralized approaches to policy" (Lalor and Hickey, 2014, pp. 1). Nonetheless, the relationship between environmental science and environmental policy remains problematic. Hayward (2006) highlights difficulties in this relationship such as the effort required, and lack of consensus, which can lead to frustration. Hayward also stresses that scientific uncertainty presents a major challenge in policy-making. Trudgill and Richards (1997) point to clear challenges: research can make problems more complex; some policy-makers see complexity as a reason for procrastination, while others may find the complexity frustrating; and public consultation (“downstream”) approaches are sometimes too simple to address increasingly complex environmental problems. The complexity of environmental problems has opened a space for new actors to contribute to policy-making such as lobby groups, the media (including science journalists), board advisory members, researchers, scientists and consultants. However their roles remains open to contradiction. The literature suggests that consultants play a key role in the policy-making process (e.g., Van Niekerk, 2008; Dolowitz and Marsh, 2000), but little research has explored the internal dynamics of consultancies themselves or the ways that policy-makers engage consultants to fill gaps in their expertise (Weitkamp and Longhurst, 2012). 
The public and other interest group representatives have "high expectations for the ability of science to provide important information to managers when making decisions" (Steel at al., 2004, p.11). This positive interest in the role of scientific advice has led to strong support for more prominent roles for scientists in the policy process (Steel at al., 2004) and there is a view that scientists ought to be involved in the policy process as sources of objective information (Mazur, 1981). However, in a recent study in Brazil, researchers identified tensions and barriers, for example scientists try to adopt politically neutral positions and decision makers accuse scientists of 'academicism' and ‘disengagement from reality’ (Carneiro and da-Silva-Rosa, 2011).

Beyond the role of scientists, there are also other types of stakeholders who might take an important role, including that of the environmental consultant. Environmental consultants are not academics per se, but they may act as an effective mediator between the scientific community and policy-makers. And yet little is known about their perspectives and roles in the policy-making cycle. This paper explores the role played by environmental consultants in the policy-making process. For the purpose of this work, environmental consultants are defined as those who provide technical information and have knowledge of and access to decision-makers, making them well positioned to provide advice (Suter and Cormier, 2012).

This pilot study focused on one European country (Portugal) to develop and generate hypotheses about the role and influence of environmental consultants as knowledge-brokers in the process of constructing environmental policy and adapting EU legislation into the national and local environmental framework. As such, it can be seen as a case study that can offer insight into the likely processes in similar countries. The 
research involved an array of policy-makers at national and local level, and environmental consultants. In the first part of this paper we explore the role of knowledge-brokers in the policy-making cycle, while in the second part the relationship between policy-makers and environmental consultants is investigated.

\section{Knowledge brokers in policy-making}

"Knowledge brokers" are typically intermediaries charged with the specific role of encouraging the use of academic research by non-academic research users (Gagnon, 2011), including, amongst other groups, the general public, businesses, industry and policy-makers. In a policy-making context, knowledge brokers are mediators who have the ability to understand the role of the policy-maker and the role of the researcher (CHSRF, 1999). As Gagnon (2011, p.27) puts it, "the rationale for knowledge brokers is the need to provide an intermediary who could facilitate collaborations between researchers and research users and find research evidence to shape decisions, be able to assess this evidence, interpret it and adapt it to circumstances and identify emerging management and policy issues that research could help inform". As their tasks include generating, interpreting, organising and communicating research-based information, knowledge brokers have the potential to improve environmental policies by encouraging policy-makers to draw on evidence (Gagnon, 2011). Van Kammen et al. (2006, p. 608) argue that "knowledge brokering is a promising strategy to close the 'know-do gap' and foster greater use of research findings and evidence in policy-making."

Environmental consultants can be described as knowledge brokers since they act as intermediaries between scientific evidence and policy-makers. These experts may assume 
a variety of roles when working with governments and policy-makers and may be brought in for a range of reasons: when there is not enough internal expertise to produce a policy framework (Desveaux et al., 1994); when governments seek advice and support on specific technical problems (Ames and Keck, 1997); when sources of information regarding environmental problems are needed, as well as advice on interpretation of rules (May and Winter, 1999); and when a link between clients and stakeholders is essential (Weitkamp and Longhurst, 2012). Suter and Cormier (2012, p.1153) state that 'good decision-makers want all the advice they can get when making tough environmental decisions' and environmental consultants can fulfil this role. Consultants can also "to some extent take on the role of local government in environmental decision making processes" (Van Niekerk, 2008, p.174). Finally, environmental consultants are often used to evaluate the impact of policy and to collect and select scientific evidence in preparation for policy-making (Davenport et al., 2010).

Consultants are brought in because they are typically more familiar with particular issues, have more specific knowledge and 'may have prior experience with similar assessments and the outcomes of management actions' (Suter and Cormier, 2012, p.1153). Suter and Cormier (2012, p.1153) provide a summary of the expertise and role of environmental consultants: 'they bring important expertise and world views distinct from engineers, lawyers, and policy experts who often serve as decision-makers. Hence, beyond providing technical estimates of risks, they can provide a depth and breadth of understanding of conditions, implications, and options that would not otherwise be available to decision-makers'. The relationship between consultants and policy-makers can, nevertheless, have its pitfalls. Ames \& Keck (1997) note that consultants' findings 
may be ignored if they are unpalatable to the commissioning policy-makers, whilst consultants may lack sufficient skills and credibility to overcome a lack of leadership from within the policy community (Desveaux et al., 1994). It has also been noted that policy-makers may focus on fulfilling legal requirements and end up overlooking the outcomes and benefits of consultation (Leksmono et al., 2010).

\section{Case study}

This small-scale exploratory study used one European country (Portugal) as a case study and involved policy-makers at different levels of governance as well as environmental consultants. It examined the role of consultants in the policy-making process, particularly their role in providing scientific expertise, from the perspective of environmental consultants and national and local government policy-makers.

Portugal is a small European country with different tiers of governance: a large portion of environmental legislation comes from the European Commission, and is then adapted by the national government, before it is implemented both by national and local governments. This model is widely used in Europe; Steurer (2009) describes the example of sustainable development in Austria, which cuts across "boundaries between vertical tiers of policy-making, from supranational institutions like the European Commission, via federal and county governments, to city halls" (Steurer, 2009:6). As a case study, this research can therefore be translatable to other countries and contexts.

The study reported here investigated the role undertaken by environmental consultants in the policy-making process. Specifically, the authors aimed to understand: 
1) The role of environmental consultants in the policy-making process in Portugal.

2) Environmental consultants' relationship with scientific evidence

3) The relationship between consultants and policy-makers.

\section{Methodology}

The research comprised a mixed methods approach, combining qualitative (semistructured interviews) and quantitative data (online survey). Interviews provide direct access to the insights, experiences and opinions of the participants, providing rich data from which to develop themes (Tong et al., 2007). In particular, semi-structured interviews are an appropriate qualitative method to explore the perspectives of key players in the policy-making process, as they allowed consultants to reflect on and express the complexities of the relationship with policy-makers. Supplementing this with quantitative data allowed us to draw data from a wide sample of environmental consultants and offered a high degree of reliability, since quantitative techniques are easily replicated and the data produced can be independently verified (McNeill and Chapman, 2005). This mixed methods approach allowed us to explore the roles of the key actors in the policy-making process and to assess the relationships between them.

\subsection{Semi-structured interviews: design, recruitment and sample characterisation}

The interview schedule included open-ended questions that allowed participants to provide answers in their own terms (Groves et al., 2004); these questions were "used to 
prompt open and detailed discussion and ensure all key areas were covered" (Weitkamp and Longhurst, 2012), whilst also allowing for unanticipated responses. The questions concerned the stages of the policy-making cycle in which consultants become involved, the roles played by environmental consultants at various points in that cycle and the nature of their work. The questions also explored the use of scientific information (how frequently this happened as well as the types of resources used) and the relationship between consultants and policy-makers. All interviews finished with a free comment question, where the participants could add any information they thought relevant.

The interview schedule was planned and designed in English and then translated to Portuguese. The interviews were conducted in Portuguese, the native language of the interviewees, to eliminate any barriers that might arise from a potential lack of participants' confidence in spoken English and to increase informants' willingness to participate and to facilitate open and frank discussion. For consistency one researcher conducted all the interviews, predominantly via telephone (one interview occurred faceto-face). Interviews lasted between 15 and 30 minutes and were digitally audio-recorded. The research was conducted in accordance with the ethical procedures of the University of the West of England's Research Ethics Committee.

To gather a variety of participants within the environmental policy-making process, we invited key players from the national and local governments and environmental consultants from a range of consultancies. Eighteen in-depth interviews were conducted: eleven with environmental consultants, four with national government members and three with local government key actors. 
Participants were recruited through a combination of convenience sampling (based on previous projects), supplemented by Internet searches focussing on evidence of involvement in policy-making. The participants were all Portuguese nationals, and all worked in Portugal on environmental research, issues or legislation. National government participants were senior representatives of several national government departments in charge of environmental areas (e.g. water resources, biodiversity). Local government participants were identified for their role as "Vereador do Ambiente" (a Local Councillor with responsibility for the Environment), which is the most relevant local government role in relation to environmental policy-making. Environmental consultants worked with a wide range of policy-makers (Table I) and were employed by consultancies that worked across a wide range of environmental issues from Local Agenda 21, to waste policy and forest fire protection.

\subsection{Quantitative survey: design, recruitment and sample characterisation}

Based on a preliminary analysis of the interview data, topics for further exploration were identified. These focused on the practical experience of environmental consultants engaging with policy-makers and their relationship with scientific evidence. An online survey was designed based on these topics. The researchers decided on an online survey, as it was a convenient way to quickly and effectively question consultants in another country. Also, online surveys have the advantage of serving as extra encouragement and motivation to respondents to complete the survey, since there is no human interviewer (Couper, et al., 2002), making participants more comfortable and honest. 
A list of environmental consultants working in Portugal was compiled, using internet searches similar to those described before. Whereas for the in depth interviews, we deliberately selected environmental consultants from different consultancies, for the questionnaire we included multiple informants from each consultancy. Furthermore, the email invited informants to pass the survey on to their colleagues (as it was not always possible to identify all potentially relevant informants via the internet). The exact number of consultants invited is uncertain but likely to be higher than the 130 invited directly by the research team. Participants were contacted via email inviting them to take part in the research; the email provided a link to the online survey and one reminder was sent two weeks after the original email.

The survey was presented in Portuguese and results translated into English. The online survey comprised 15 open-ended and closed questions. Closed questions present the respondents with a list of options and do not discriminate against less responsive participants (De Vaus, 2002). Open-ended questions were used when more reflective answers were needed, but were kept to a minimum (only two out of a total of 15 questions were open-ended), since they tend to have a lower response rate and maybe seen as tedious by the respondents (De Vaus, 2002).

A total of 111 completed surveys were available for analysis. Respondents represented a nearly equal gender balance: $53 \%(n=58)$ self-identified as male and $47 \%$ $(n=52)$ as female. These results are in line with the latest demographic data available, which shows that in Portugal in $2009,53.2 \%$ of the employed population were men and $46.8 \%$ were women (INE, 2009). In terms of career, most listed their current roles as consultant $(48 \%, n=43)$, director $(30 \%, n=33)$, team coordinator $(24 \%, n=26)$ or manager 
$(17 \%, \mathrm{n}=19)$. Other roles listed were project supervisor, client liaison and researcher. A few described their role as scientific coordinators $(6 \%, n=7)$. Survey respondents indicated that they had worked with a variety of partners (Table II). These findings support data from the interviews, showing that Portuguese environmental consultants frequently work with a wide variety of policy-makers.

\subsection{Data analysis}

Interviews were transcribed in Portuguese and translated into English. In analysing the transcripts, the researchers looked for common (most frequent) themes in answer to each question and/or common and emergent theme areas, sorting them into excerpt files to locate patterns throughout the interviews. Emergent themes were subjected to further analysis, using the qualitative software NVivo 8. Data from the survey were also translated into English and answers to each question analysed using Microsoft Excel.

\section{Results and Discussion}

\subsection{How environmental consultants engage with policy-makers}

Policy-making involves several policy processes, which form a cycle of decisions and policies. Knill and Tosun (2008 p9) define the cycle as consisting of (1) agenda setting, (2) policy formulation, (3) policy adoption, (4) implementation, and (5) evaluation (Figure 1). Our research shows that environmental consultants take on a variety of roles in working with policy-makers, indicating they engage with policy-makers in several 
ways. For example, Portuguese national government interviewees mentioned that environmental consultants may advise the government on financial, legal and technical issues, engaging with policy-makers as information gatherers. Other consultants described how their services have been used by policy-makers, illustrating more of a guidance role:

The role of these consultants is for example a guidance role: at some point they are asked to work on certain types of projects and what they do is what we ask them to do; this happens in the area of economic and legal issues. (Interviewee 06, National Government Member)

This comment raises questions on whether or not the consultants are genuinely free to offer advice and it seems to point to an instrumental use of consultants: they do what they are asked to do. This engagement with policy-makers was previously described by Suter and Cormier, who state that consultants performing an advisory role should be 'appropriately modest and provide the advice that is solicited' (Suter and Cormier, 2012, p. 1154)

In addition to advising policy-makers on a variety of areas and issues, environmental consultants may also engage with policy-makers as decision advisers, summarising the scientific evidence and offering advice that will help policy-makers make an appropriate decision:

In general, it works like this: we have a pre-identified problem and what happens in these cases is that we take it to the consultant and say: analyse this problem and produce information so I can make the best 
decision. We never tell a scientific consultant to pre-write the result, there is no such thing. (Interviewee 21, National Government Member)

This role as decision advisers was also highlighted by the consultants themselves. One interviewee went on to explain his company's standards and modus operandi, which reflects the importance they give to integrating scientific evidence into their work:

In order to make the projects feasible, we must know very well the reality (...). And to know very well is often to know more than the decision maker. What we do is to provide our studies with the best possible information; as much information as possible and as accurate as possible, just like any other research group. This provides in an unbiased way, the best information, allowing someone to decide on it; that's how we work. (Interviewee 01, Environmental Consultant)

Our study suggests that in Portugal policy-makers rely on consultants for information and advice. This is in line with the findings of Van Niekerk (2008) who argues that the increasing reliance of policy-makers on consultants highlights the growing importance of this group in the policy process. Weitkamp and Longhurst (2012) caution that reliance on environmental consultancies has limitations and note that policy-makers need to be aware that environmental consultancies are businesses that seek to make a profit. This business-oriented approach can limit the ability of consultancies to provide the range of information and advice needed to evaluate policy options if sufficient resources are not made available by policy-makers.

Asked about the potential role of environmental consultancies, national government interviewees confirmed that they frequently work with consultants while writing, 
creating, reviewing and implementing environmental policies. One participant stated that they "almost always" work with consultants: consultants are asked to carry out the work, while the governmental institution plays mainly a supervisory role.

Our role is fundamentally to coordinate the projects. As a result, the actual work [writing, creating, reviewing and implementing environmental policies] is always done via consultants. Realistically, with one exception or another, there is no direct production of work [from us]; we only take on the role of coordination of work undertaken by external consultants. (Interviewee 6, National Government Member)

A similar role was undertaken by environmental consultants in South Africa: "The 'environmental consultants do the work' story line indicates that the environmental consultants are the service providers and therefore responsible for collecting existing information, integrating specialist reports, including the issues and concerns from the public participation process. In contrast, the public officials are responsible for steering or directing the project" (Van Niekerk, 2008, p.171). The scenario described by Van Niekerk (2008) corresponds to one of the many roles described by our interviewees.

The involvement of environmental consultants was viewed as important by national government interviewees, since it can enhance the credibility of decisions. Furthermore, being politically neutral and independent was seen as advantageous:

\section{(...) and I asked [the environmental consultancy] for an independent}

opinion. The scientific team provided me that independent opinion, and that really helped me making the best decision. (Interviewee 21, National Government Member) 
However, this can create issues for environmental consultants, who may be used by policy-makers to legitimise political action and offload accountability (Blake and Mouton, 1990).

Local government participants confirmed that they also call upon the services of environmental consultants, though less frequently than national government. The results indicate that local government make use of consultancy sources to meet particular needs, for instance, when the local governance structures do not have the necessary manpower or skills.

The significant and broad roles of environmental consultants in the policy-making process in Portugal were confirmed by the consultants' survey. Respondents indicated that they were involved throughout the several stages of the policy-making cycle, with $77 \%(\mathrm{n}=40)$ indicating they were involved in providing evidence and $67 \%(\mathrm{n}=35)$ involved in appraising the options. Figure 2 provides further information.

When we draw together the outcomes from the interview and questionnaire data (Figure 2), our findings indicate that consultants play key roles throughout the policymaking cycle. As an interviewee put it:

When developing environmental policies, the market requests require that we work in all phases, especially in terms of planning, implementation, verification and review, with a view to continuous improvement [of the environmental policy]. (Interviewee 15, Environmental Consultant)

However, results also suggest that when policy-makers request the services of consultants their role lies in the 'information' or 'consultation' categories, not in more participative approaches, as identified by Bishop and Davis (2002) in Australia and 
Weitkamp and Longhurst (2012) in the UK. From our data, a picture is emerging of the different roles of consultants in the process of developing evidence-based policy, one of which appears to be similar to the role adopted by scientists when working with policymakers. Ruseva (2007) argues that scientists typically act as 'simple inventors' rather than taking on more powerful roles such as 'policy entrepreneurs' or 'agenda setters'. Nonetheless, one participant in our research highlighted an important bridging role that environmental consultants play facilitating the transfer of knowledge from the scientific community to the policy arena:

Between researchers and policy-makers there will always be a need for a communication link. This link allows understanding between parties, as well as the incorporation of scientific research and support for policymaking. Consultants are the best actors to bridge this gap. If this process is supported by a 'place' where information is concentrated, with easy access and understanding, this will surely allow us to achieve better results. (Survey participant 72, Environmental Consultant)

Environmental consultants play an important role in the policy-making process in Portugal: they are one of the key bridges between scientific evidence and decisionmakers. The results also highlight the different ways that environmental consultants engage with policy-makers: offering advice, as information gatherers, knowledge brokers, as well as being instrumental in the policy-making process. 


\subsection{Environmental consultants as knowledge brokers and their relationship with scientific evidence}

Environmental consultants are not the only key actors in the environmental policymaking process: scientists and researchers are also frequently involved; scientists, as key stakeholders and holders of expert knowledge, have a role to play in the resolution of

public environmental decisions. Although consultants can take up the role of knowledge brokers, gathering and selecting scientific evidence and informing decision makers in the context of policy-making (Davenport et al., 2010), the information provided can only be as good as the sources used by and the expertise of the knowledge brokers. This sourcing of information is a critical aspect of developing evidence-based policy. Another critical aspect is the interaction between actors: a recent study indicates how crucial it is the establishment of good relationships between knowledge brokers and policy-makers and how important it is that they interact (Saarela and Rinne, 2016). We investigated the nature of information sources used by environmental consultants in both the qualitative interviews and survey. While conducting work commissioned by policy-makers, all consultants interviewed confirmed they use an extensive range of information sources, with academic papers $(\mathrm{n}=11,100 \%$ of the participants $)$, newsletters and technical reports $(n=6)$ and direct contact with scientists $(n=5)$ being the most common. Consultants also regularly attend scientific meetings and some host or support $\mathrm{MSc}$ and $\mathrm{PhD}$ students, suggesting that some, at least, have significant research expertise themselves. The survey participants all used at least one source of scientific evidence (Figure 3). The majority stated that they regularly used technical reports, academic papers and conferences and scientific meetings as sources of information on environmental research. This shows that 
using a variety of sources, rather than just one type of scientific evidence is a widespread practice amongst Portuguese environmental consultants. Ultimately, this means that policy-makers who request the services of these environmental consultants will have access to an array of "digested" scientific evidence which can then be integrated into policy. A similar type of service is provided by environmental consultants in the UK, who reported that they "routinely filter and present information in accessible formats to different stakeholder groups", including policy-makers (Weitkamp and Longhurst, 2012).

All consultants responding to the survey stated that they search relevant literature for new scientific evidence. The majority indicated that they searched the literature once a week $(44 \%, n=37)$ or once a month $(33 \%, n=38)$ while only $1 \%(n=1)$ report searching scientific literature only once a year. This clearly shows that Portuguese environmental consultants are reporting that they are actively engaged with the scientific literature. Nevertheless, consultants report that sifting through academic journals is an overwhelming task $(68 \%$ agree, $n=57)$ perhaps reflecting their wide range of roles - it is not inconceivable that a consultant will be managing projects across a range of environmental policy issues. Only one participant stated that it was easy to carry out this task. When asked about how easy it is to judge the quality of research reports published on the Internet (i.e. not in academic journals) the opinions were mixed: $20 \%(\mathrm{n}=17)$ found it neither easy nor difficult, $39 \%(n=33)$ found it easy and $40 \%(n=34)$ found it difficult. However, the majority agreed that keeping up to date takes too long (54\%, $n=45)$.

In addition to being knowledge brokers and acting as intermediaries between scientific evidence and policy-makers, environmental consultants also reported 
undertaking research, assuming, in these situations, a very different role. Nine of 11 interviewees confirmed that the consultancies they work for undertake research to support policy development, suggesting that they are themselves familiar with scientific studies and methodologies and perhaps explaining their confidence in assessing the quality of research reports.

We have a department of $R \& D$ and that way we, internally (within the consultancy), develop methodologies that allow us to go further and answer the challenges being posed to us, and do the work that we are asked to do. (Interviewee 1, Environmental Consultant)

Mainly we do applied research projects in which we raise a number of issues that require us to do our 'homework' and to carry out research. We research the concept, the state of the art, etc. You must do research, it is mandatory to be aware of what is happening. (Interviewee 4, Environmental Consultant)

Portugal is a small, close-knit country where policy-makers are working on improving the relationship of science and governance. This may mean the scenario described in this study may not be translated to other countries and it would be interesting to conduct further work to find out why. For example, a study carried out in the UK reports that environmental consultants do not usually produce scientific evidence (Weitkamp and Longhurst, 2012). 


\section{Summary and conclusions}

This study shows that, in Portugal at least, environmental consultants act as knowledge brokers (as articulated by Gagnon, 2011 and Van Kammen, 2006), facilitating policy makers' access to scientific information, and translators, presenting scientific information in a language and format suitable for the policy community, as well as occasionally undertaking original scientific research. It also suggests that environmental consultants are involved throughout the policy-making cycle and that in Portugal, policymakers rely on these experts for information and research. Environmental consultants were called upon by policy-makers to provide evidence that supports policy-choice, allowing the policy makers to evaluate different options. This suggests that environmental consultants are expected to analyse sometimes conflicting or uncertain research and present this in a way that policy makers can use in their own decision making processes. Furthermore, the environmental consultants will likely have to analyse and present research arising from a number of disparate disciplines given the complex and overlapping nature of environmental problems. Thus, the role of environmental consultants goes beyond that of 'simple inventors' (Ruseva, 2007) or translators as they fulfil a need (to analyse multidisciplinary evidence and present this in the context of policy options) that scientists, seeking to maintain their neutrality, appear unable to meet. Nevertheless, we did not find any evidence of environmental consultants acting as either agenda setters or policy entrepreneurs, probably because the nature of the business environment in which they work, means that their efforts are focused on the tasks they are asked (and paid) to do (Weitkamp \& Longhurst, 2012). 
We also did not find evidence of environmental consultants being asked to use scientific evidence instrumentally to support policy decisions taken elsewhere or in advance. As knowledge brokers, promoting and encouraging the use of scientific evidence, environmental consultants are involved in writing, creating, implementing and reviewing environmental policies, though they may also take up other roles such as acting as scientific informants and financial, legal and technical advisors. Although not as common as these roles, consultants may also occasionally take on the role of researcher, as commissioned by the policy-makers. As such, consultants need to be familiar and upto-date with scientific evidence.

Because environmental consultants act as scientific informants, knowledge brokers and occasionally researchers, their relationship with scientific evidence is crucial. Our study shows that using scientific evidence while working with and for policy-makers is a widespread practice amongst Portuguese environmental consultants. These practices enable policy-makers to gain access to an array of scientific evidence, using the same sources of information used by scientists and requiring a high level of scientific understanding.

\section{Acknowledgments}

The authors are very grateful to all the interviewees who generously donated they time, knowledge and experience. This project was supported by the European Commission, Directorate General Environment through contract no: ENV.G.3/SER/2007/0049 


\section{References}

Ames, B and Keck, ME. (1997) 'The Politics of Sustainable Development:

Environmental Policy Making in Four Brazilian States', Journal of Inter-American Studies and World Affairs, Vol. 39 No.4, pp.1-40.

Bishop, P and Davis, G. (2002) 'Mapping public participation in policy choices', Australian Journal of Public Administration, Vol. 61 No.1, pp.14-29.

Blake, RR and Mouton, JS. (1990) Consultation: The Handbook for Individual and Organization Development, $2^{\text {nd }}$ ed, Boston, Addison-Wesley Publishing.

Carneiro, MJ and da-Silva-Rosa, T. (2011) 'The use of scientific knowledge in the decision making process of environmental public policies in Brazil', Journal of Science Communication, Vol. 10, No.01, A03.

Canadian Health Services Research Foundation (CHSRF). (1999) Issues in Linkage and Exchange between Researchers and Decision-Makers: Summary of workshop convened by CHSRF, May.

Couper, M, Traugott, M and Lamias, M. (2002) 'Web Survey Design and Administration', Public Opinion Quarterly, Vol. 35, pp.230-53.

Davenport, F, Kilfoyle, M, Quick, F and Weitkamp, E. (2010) 'Environmental Research: An analysis of policy makers needs'. Poster presentation at the $3^{\text {rd }}$ European Communication Research and Education Association (ECREA) Conference (12-15 October), Hamburg, Germany.

Desveaux, JA, Lindquist, EA and Toner, G. (1994) 'Organizing for Policy Innovation in Public Bureaucracy: AIDS, Energy and Environmental Policy in Canada', Canadian Journal of Political Science, Vol. 27, No. 3, pp.493-528. 
De Vaus, D. (2002) Surveys in Social Research. Social Research Today. ${ }^{\text {th }}$ ed. New York: Routhedge.

Dolowitz, D P and Marsh, D. (2000) 'Learning from Abroad: The Role of Policy Transfer in Contemporary Policy-Making', Governance, Vol. 13, pp.5-23.

European Commission. (2008) Scientific evidence for policy-making. DirectorateGeneral for Research Socio-economic Sciences and Humanities. EUR 22982 EN.

Gagnon, ML. (2011) 'Moving knowledge to action through dissemination and exchange', Journal of Clinical Epidemiology, Vol. 64, pp.25-31.

Groves, RM, Fowler, FJ, Couper, MP, Lepkowski, JM, Singer, E and Tourangeau, R. (2004) Survey Methodology. Wiley Series in Survey Methodology. WileyInterscience, $1^{\text {st }}$ Edition.

Hayward, SF. (2006) ‘Environmental Science and Public Policy’. Social Research, Vol. 73, No.3, pp891-914.

Instituto Nacional de Estatística (INE). (2009) Statistical Yearbook of Portugal - 2009 [online].https://www.ine.pt/xportal/xmain?xpid=INE\&xpgid=ine_publicacoes\&PUB LICACOESpub_boui=104996740\&PUBLICACOESmodo=2 (Assessed 18th May 2016).

Knill,C and Tosun, J. (2008) 'Policy Making. Working Paper 01/2008', Chair of Comparative Public Policy and Administration, Department of Politics and Management. University of Konstanz. Konstanz, Germany. 
Lalor, BM and Hickey, G. (2014) 'Strengthening the Role of Science in the Environmental Decision-Making Processes of Executive Government', Organization \& Environment, Vol. 27, No.2, pp.161-180.

Leksmono, N, Dorfman, P, Burnet, F, Gibbs, DC, Longhurst, J, Weitkamp, E. (2010) 'Enhancing Consultation Practices in Air Quality Management in Local Authorities', Journal of Environmental Planning and Management, Vol. 53, No.5, pp.559-571.

May, PJ and Winter, S. (1999) 'Regulatory Enforcement and Compliance: Examining Danish Agro-Environmental Policy', Journal of Policy Analysis and Management, Vol. 18, No.4, pp.625-651.

Mazur, A. (1981) The Dynamics of Technical Controversy. Washington, DC, Communication Press.

McNie, E. (2007) 'Reconciling the supply of scientific information with user demands: an analysis of the problem and review of the literature', Environmental Science \& Policy, Vol. 10, pp.17-38.

McNeill, P and Chapman, S. (2005) Research Methods. 3rd ed. Florence, KY: Routledge.

Ruseva, TB. (2007) 'Scientific Elites as Policy Entrepreneurs: Is There a Role for Scientists in Congressional Climate Change Policy?', Paper presented to the Science \& Technology in Society: An International Multidisciplinary Graduate Student Conference, American Association for the Advancement of Science, Washington, DC, March 31- April 1.

Sardo, M and Weitkamp, E. (2012) 'Exploring the ways environmental science is used and valued by policy-makers in Portugal: a case study', Journal of Science Communication, Vol. 11, No.3, C05. 
Saarela, SR and Rinne, J. (2016) 'Knowledge brokering and boundary work for ecosystem service indicators. An urban case study in Finland', Ecological Indicators, Vol. 61, pp.49-62.

Steel, B, List, P, Lach, D and Shindler, B. (2004) 'The role of scientists in the environmental policy process: a case study from the American west', Environmental Science \& Policy, Vol. 7, pp.1-13.

Steurer, R. (2009) 'Sustainable development as governance reform agenda:

An aggregation of distinguished challenges for policy-making', Discussion Paper 1-2009. Institute of Forest, Environmental, and Natural Resource Policy, University of Natural Resources and Applied Life Sciences, Vienna (BOKU).

Suter, G. W. \& Cormier, S. M. (2012). Two Roles for Environmental Assessors: Technical Consultant and Advisor. Human and Ecological Risk Assessment: An International Journal, 18(6), pp. 1153-1155.

Tong, A, Sainsbury, P and Craig, J. (2007) 'Consolidated criteria for reporting qualitative research (COREQ): a 32-item checklist for interviews and focus groups', International Journal of Quality in Health Care, Vol. 19, No.6, pp.349-357.

Trudgill, S and Richards, K. (1997). 'Environmental Science and Policy: Generalizations and Context Sensitivity', Transactions of the Institute of British Geographers, Vol. 22, pp.5-12.

Van Kammen, J, de Savigny, D and Sewankambo, N. (2006) ‘Using knowledge brokering to promote evidence-based policy-making: the need for support structures', Bulletin of the World Health Organization, Vol. 84, No.8, pp.608-612. 
Van Niekerk, M. (2008) 'The role of environmental consultants in municipal environmental decision making: a discourse analysis of the strategic environmental assessments (sea) of the Kwadukuza and Rustenburg municipalities', Masters Thesis. University of KwaZulu-Natal, Durban.

Weitkamp, E and Longhurst, J. (2012) ‘Mediating consultation: Insights from private sector consultants involved in air quality consultations.', Journal of Environmental Planning and Management, Vol. 55, No.1, pp.113-125.

\section{Tables and Figures}

\begin{tabular}{ll}
\hline Public and private industry & $\mathrm{n}=6$ \\
\hline Local Government & $\mathrm{n}=9$ \\
National Government & $\mathrm{n}=7$ \\
National Governments of other countries & $\mathrm{n}=1$ \\
\hline
\end{tabular}

Table I. Range of policy-makers that interview participants have worked with (total $n$ adds up to more than 18 since consultants work with several different groups).

\begin{tabular}{ll}
\hline Local government & $71 \%(\mathrm{n}=37)$ \\
\hline National government & $67 \%(\mathrm{n}=35)$ \\
Industry (public and private sectors) & $48 \%(\mathrm{n}=25)$ \\
European Commission & $27 \%(\mathrm{n}=14)$ \\
\hline
\end{tabular}


Non-governmental organisations $\quad 25 \%(n=13)$

National governments of other countries $\quad 8 \%(n=4)$

Table II. Range of policy-makers that survey participants have worked with.

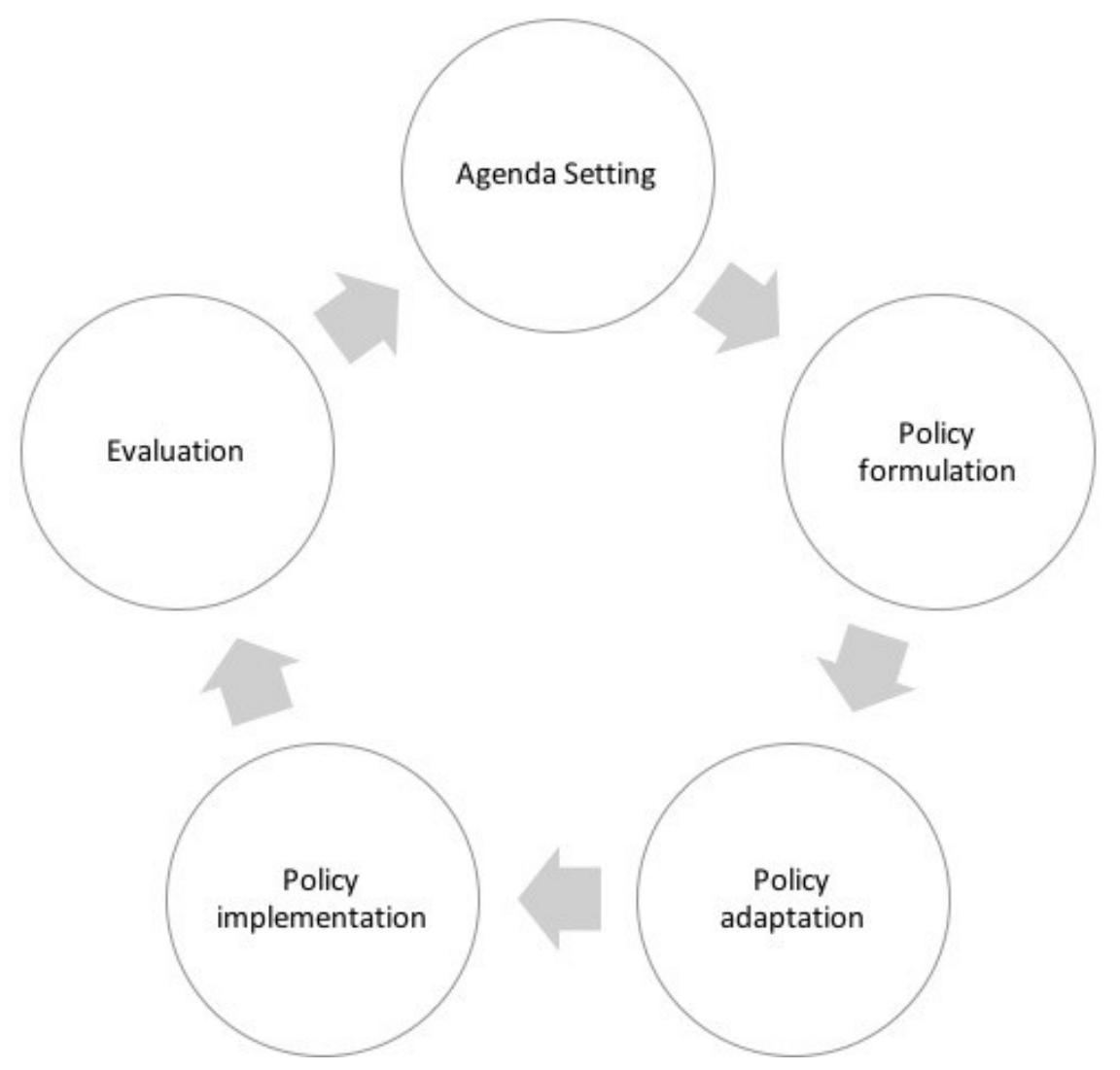

Figure 1. Policy cycle based on Knill and Tosun (2008 p9). 


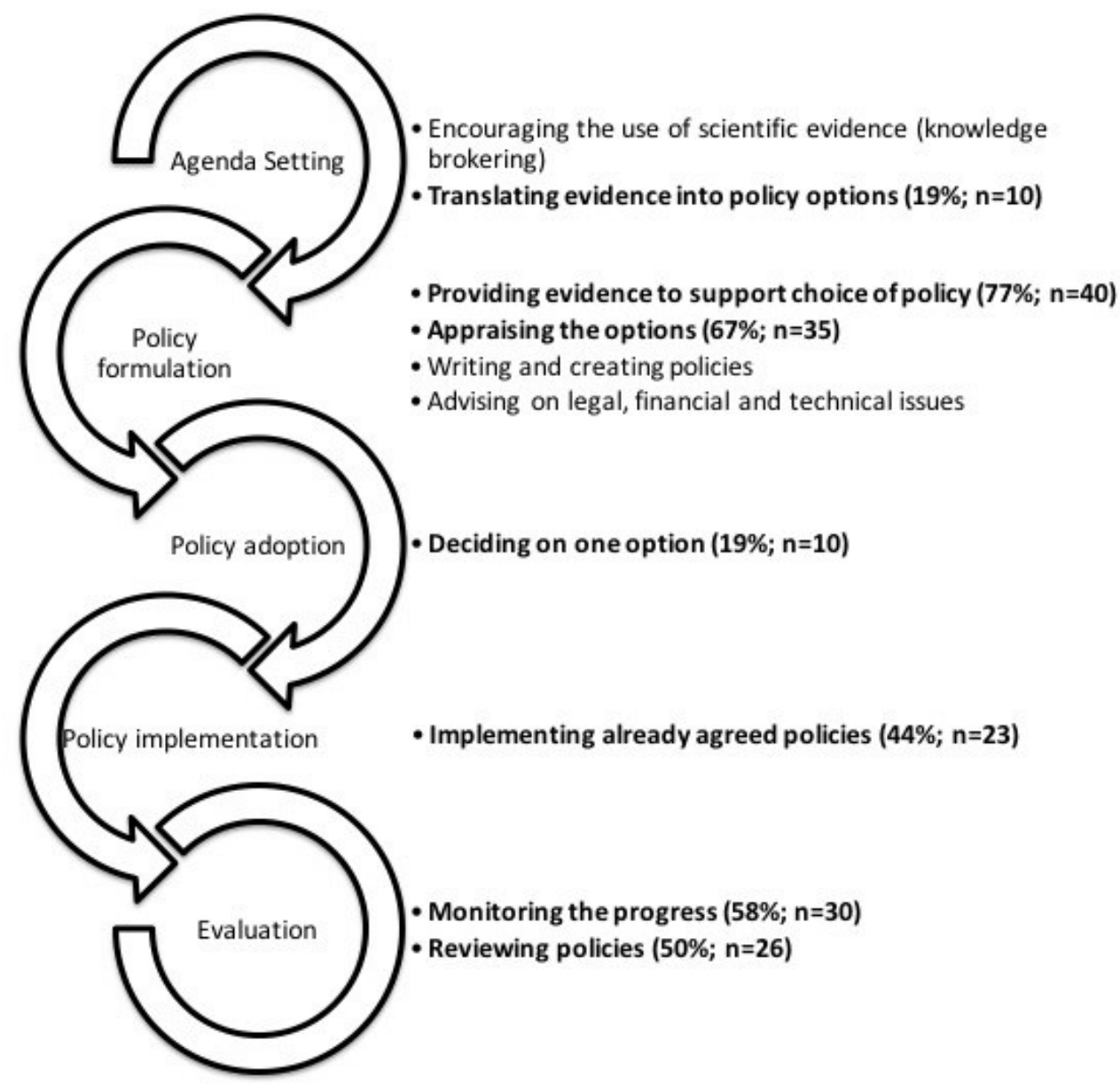

Figure 2. Environmental consultants' involvement in the policy-making cycle (note:

results in bold taken from online questionnaire; otherwise results taken from interviews). 


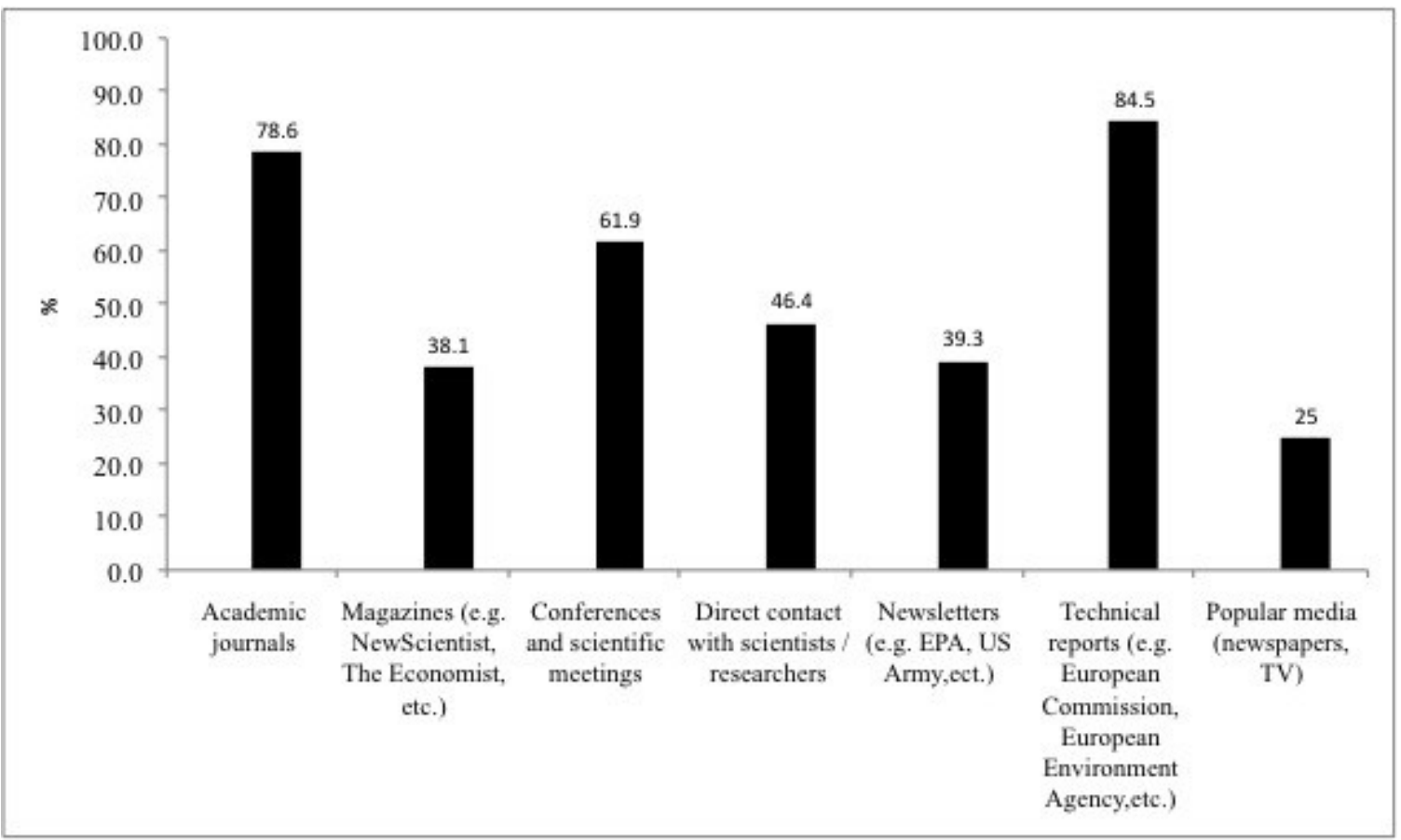

Figure 3. Scientific evidence used by Portuguese environmental consultants (data from online questionnaire). 